\title{
AVALIAÇÃO HIGIÊNICO-SANITÁRIA DE LINGUIÇAS TIPO FRESCAL COMERCIALIZADAS NOS MUNICÍPIOS DE TRÊS CORAÇÕES E LAVRAS-MG
}

\author{
Evaluation of hygienical-sanitary sausage type frescal commercialized in \\ the cities of Três Corações and Lavras - MG
}

\author{
Simone Cristina Marques ${ }^{1}$, Cleube Andrade Boari ${ }^{2}$, Carolina Carvalho Brcko ${ }^{3}$, \\ Adenilde Ribeiro Nascimento ${ }^{4}$, Roberta Hilsdorf Piccoli5
}

\begin{abstract}
RESUMO
Com o presente trabalho, objetivou-se avaliar a qualidade higiênico-sanitária de lingüiças tipo frescal, em função do potencial risco que estes produtos representam para a saúde pública. Para a condução de tal pesquisa, amostras foram aleatoriamente coletadas no município de Três Corações $(n=20)$ e Lavras $(n=20)$, ambos situados no Estado de Minas Gerais. As análises microbiológicas, conduzidas de acordo com o ICMSF (1982), constaram da enumeração de coliformes totais e termotolerantes (colimetria), quantificação e identificação bioquímica de Staphylococcus coagulase positiva e Salmonella spp. Não foi detectada a presença de Salmonella spp. em nenhuma das amostras. Os valores para contaminação por coliformes termotolerantes encontraram-se dentro do intervalo de $10^{1}$ a $10^{4} \mathrm{NMP} / \mathrm{g}$. Em $14 \%$ das 40 amostras analisadas foi detectado Staphylococcus coagulase positiva acima do limite estabelecido pela legislação vigente. Pelos valores encontrados, as lingüiças analisadas não são produzidas dentro de padrões de higiene satisfatórios, sendo um potencial causador de toxinoses e infecções alimentares aos consumidores.
\end{abstract}

Termos para indexação: Lingüiça tipo frescal, microbiologia, qualidade.

\begin{abstract}
The aim of this work was to evaluate the microbial quality of sausage in function of the potential involvement of these products in public health questions. Samples were randomly collected in Três Corações $(n=20)$ and Lavras $(n=20)$, both cities of Minas Gerais, Brazil. Microbiological analysis (ICMSF, 1982) were conduced to quantify, isolate and identify coliforms, Staphylococcus aureus positive coagulase and Salmonella spp. Salmonella spp was not found in none of samples. Counts of coliforms were between $10^{1}$ to $10^{4} \mathrm{MPN} / \mathrm{g}$. Counts Staphylococcus positive coagulase were above the limit established by food legislation in $14 \%$ of the samples. In function of values found in this research sausages analyzed were elaborated under inappropriated conditions of hygiene and may represent risks to consumers.
\end{abstract}

Index terms: Sausage, microbial contamination, quality.

(Recebido para publicação em 3 de janeiro de 2005 e aprovado em 6 de junho de 2005)

\section{INTRODUÇÃO}

Embutidos, como lingüiças, são definidos como alimentos condimentados contidos em envoltório natural ou artificial, cuja elaboração emprega carne de bovinos, suínos ou aves, bem como suas vísceras, podendo ser cozido ou não, curado, maturado e dessecado (BRASIL, 2001; CHAVES et al., 2000).

Sua obtenção requer uma série de etapas de manipulação, o que eleva as possibilidades de contaminação por uma gama de espécies de microrganismos, patogênicos ou deterioradores, podendo comprometer a qualidade microbiológica do produto final, desde que ocorram falhas e não conformidades em seu processamento. Diversas podem ser as fontes de introdução destes agentes na cadeia alimentar, como condições inadequadas de abate e evisceração, nas quais as carcaças podem ser contaminadas por enterobactérias presentes no trato gastrintestinal (BORCH et al., 1996; TUTENEL et al., 2003). Desta forma, a qualidade do produto elaborado reflete de forma clara a qualidade da matériaprima empregada na produção e ingredientes (MAURIELLO et al., 2004; MOROT-BIZOT et al., 2006). Além destes aspectos, o colaborador envolvido na produção, bem como facilitadores, como equipamentos e utensílios, podem ser importantes fontes de contaminação, desde que inadequadamente higienizados (CHEVALLIER et al., 2006).

Dentre os microrganismos patogênicos que potencialmente podem estar presentes no produto final

${ }^{1}$ Bióloga, MSc. Ciência dos Alimentos, doutoranda em Ciência dos Alimentos no Departamento de Ciência dos Alimentos - Universidade Federal de Lavras/UFLA - Cx. P. 3037 - 37200-000 - Lavras, MG - simonemarques23@hotmail.com

2 Zootecnista, MSc. Ciência dos Alimentos, doutorando em Microbiologia de Alimentos no Departamento de Ciência dos Alimentos - Universidade Federal de Lavras/UFLA - Cx. P. 3037 - 37200-000 - Lavras, MG.

${ }^{3}$ Zootecnia, Universidade Federal de Lavras/UFLA - Cx. P. 3037 - 37200-000 - Lavras, MG

${ }^{4}$ Professora, Departamento de Engenharia Química - Universidade Federal do Maranhão.

${ }^{5}$ Professora Adjunta, Departamento de Ciência dos Alimentos - Universidade Federal de Lavras/UFLA - Cx. P. 3037 - $37200-000$ - Lavras, MG. 
destacam-se Salmonella spp., Staphylococcus aureus e Escherichia coli (HOFFMANN et al., 1996). Sendo assim, em função da presença destes agentes, produtos cárneos podem constituir sérios problemas para a saúde pública, uma vez que estas bactérias são causas comuns de toxinfecções alimentares (PARDI et al., 1993).

Pelo exposto, o objetivo do presente trabalho consiste no estudo sobre a qualidade microbiológica de lingüiças tipo frescal e a comparação dos resultados com os padrões legais vigentes (BRASIL, 2000).

\section{MATERIALE MÉTODOS}

Foram analisadas 40 amostras de lingüiças frescal adquiridas em estabelecimentos comerciais específicos do município de Lavras ( $n=20)$ e Três Corações $(n=20)$, ambas localizados no Estado de Minas Gerais. As amostras coletadas foram embaladas em filme plástico, acondicionadas em caixa isotérmica e transportadas ao Departamento de Ciência dos Alimentos, setor de Microbiologia de Alimentos da Universidade Federal de Lavras, UFLA, no qual procederam-se as análises de colimetria, enumeração e caracterização bioquímica de Staphylococcus coagulase positiva e Salmonella spp. (ICMSF, 1982).

\section{Preparo das amostras}

Foram pesados assepticamente $25 \mathrm{~g}$ de cada amostra e homogeneizados em $225 \mathrm{~mL}$ de água peptonada $0,1 \%(\mathrm{p} / \mathrm{v})$. Diluições decimais sucessivas foram realizadas em $9 \mathrm{~mL}$ de água peptonada $0,1 \%$.

\section{Enumeração de coliformes totais e termotolerantes}

A enumeração de coliformes (totais e termotolerantes) foi feita utilizando-se a técnica do Número Mais Provável (NMP) em séries de três tubos, com a realização de testes presuntivo, em caldo lauril sulfato tripsote (LST) e confirmativo em caldo Escherichia coli (EC).

\section{Contagem e identificação de Staphylococcus coagulase positiva}

Para enumeração, isolamento de colônias e identificação de $S$. aureus, empregou-se o plaqueamento em Agar Baird-Parker, com incubação a $37^{\circ} \mathrm{C} / 24-48$ horas. Colônias foram isoladas e submetidas à coloração de Gram, catalase, coagulase, termonuclease (HOLT, 1994).

\section{Pesquisa de Salmonella sp.}

Para a pesquisa de Salmonella spp. procedeu-se a etapa de pré-enriquecimento em Água Peptonada
Tamponada, com incubação a $37^{\circ} \mathrm{C} / 18$ horas. A seguir, na etapa de enriquecimento, empregou-se o Caldo Tetrationado Caldo Rappaport, os quais foram incubados a $37^{\circ} \mathrm{C} / 24$ horas. Alíquotas dos caldos de enriquecimento foram estriadas em placas contendo Agar Rambach e Agar Hectoen e incubados a $37^{\circ} \mathrm{C} / 24$ horas. Colônias suspeitas foram transferidas para tubos contendo Agar Tríplice Açúcar Ferro (TSI) e Ágar Lisina Ferro (LIA) e incubados a $37^{\circ} \mathrm{C} / 24$ horas (HOLT, 1994).

\section{RESULTADOS E DISCUSSÃO}

Pela Tabela 1, observam-se os resultados obtidos da contagem de Staphylococcus coagulase positiva, nas amostras de linguiça frescal expressos em UFC/g.

TABELA 1 - Cntagem de Staphylococcus coagulase positivo (UFC/g) em amostras de linguiça frescal.

\begin{tabular}{ccc}
\hline $\mathbf{N}^{\mathbf{o}}$ Amostras & UFC/g & Percentual \\
\hline 24 & 0 & $60 \%$ \\
9 & $10^{3}$ & $22,5 \%$ \\
2 & $10^{2}$ & $5 \%$ \\
3 & $10^{4}$ & $7,5 \%$ \\
2 & $10^{6}$ & $5 \%$ \\
\hline Total 40 amostras & & $100 \%$
\end{tabular}

Confrontando os resultados obtidos com os padrões legais vigentes, que estabelecem limite máximo de $10^{3} \mathrm{UFC} /$ g para a presença de Staphylococcus coagualse positiva, os dados demostraram que $35 \%$ das amostras de lingüiça frescal adquiridas em Lavras e Três Corações encontravamse impróprias para o consumo e podendo oferecer riscos à saúde do consumidor quanto à presença de Staphylococcus coagulase positiva (BRASIL, 2001). Dentre os Staphylococcus coagulase positiva destaca-se o Staphylococcus aureus que em países da Europa, nos Estados Unidos e Canadá é o principal agente causador de doenças transmitidas por alimentos (VIESTEL et al., 2000).

Esses achados foram superiores aos encontrados por Barbosa et al. (2003) ao avaliarem 22 amostras de lingüiças frescais de carne suína comercializadas no município de Sete Lagoas-MG, constataram que apenas uma amostra apresentou níveis de contaminação por Staphylococcus coagulase positiva superior a concentração estabelecida pela legislação vigente. Os resultados também foram superiores aos encontrados por Tessmann et al. (2001) ao analisarem 25 amostras de linguiiça frescal de carne suína da cidade de Pelotas-RS, constataram que todas as amostras encontraramse dentro dos padrões microbiológicos permitidos. 
A intensa manipulação que passa a lingüiça desde a fabricação até o consumo, e a qualidade da matéria prima podem ter sido os fatores que foram predisponentes a detecção de Staphylococcus coagulase positiva em 16 das amostras analisadas. Morot-Bizot et al. (2006) citam que as diversas espécies de Staphylococcus sp. encontradas em amostras de lingüiça estão associadas às matérias primas e às condições planta de produção. Visto que Staphylococcus sp. podem colonizar superfícies, equipamentos mal higienizados.

$\mathrm{Na}$ Tabela 2, observam-se os resultados da enumeração de coliformes termotolerantes obtidos das amostras de lingüiça frescal analisadas, expresso em NMP/g.

TABELA 2 - Enumeração de coliformes termotolerantes (NMP/g) em amostras de linguiça frescal.

\begin{tabular}{ccc}
\hline $\mathbf{N}^{\mathbf{0}}$ Amostras & NMP/g & Percentual \\
\hline 13 & $<0,5$ & $32,5 \%$ \\
7 & $10^{1}$ & $17,5 \%$ \\
6 & $10^{2}$ & $15 \%$ \\
8 & $10^{3}$ & $20 \%$ \\
6 & $10^{4}$ & $15 \%$ \\
\hline Total 40 amostras & & $100 \%$
\end{tabular}

Das 40 amostras de lingüiça frescal analisadas, 14 (35\%) encontram-se fora do padrão legal vigente que estabelece um limite máximo de $10^{3} \mathrm{NMP} / g$ para coliformes termotolerantes. Os resultados encontrados neste trabalho podem ser confrontados aos obtidos por Chaves et al. (2000) que verificaram que 33\% das amostras de lingüiça frescal comercializadas no município do Rio de Janeiro apresentaram valores de coliformes termotolerantes até dez vezes superiores aos padrões. Barbosa et al. (2003), ao avaliarem a qualidade microbiológica de 22 lingüiças frescais de carne suína no município de Sete Lagoas constataram que 15 amostras, apresentaram nível de contaminação por coliformes termotolerantes superiores ao permitido pela legislação vigente.

Não foi detectada a presença de Salmonella spp., nas amostras analisadas. Resultados diferentes foram encontrados por Tessmann et al. (2001) que ao analisarem 25 amostras de lingüiça tipo de carne suína, detectaram a presença de Salmonella sp. em 5 amostras. Chaves et al. (2000) encontraram $10 \%$ de contaminação.

Segundo Mattick et al. (2002) um dos problemas básicos no isolamento de Salmonella é o pequeno número em que se encontram em relação à quantidade de outras bactérias competidoras, o que de certa forma pode explicar a ausência deste microrganismo neste trabalho, outro problema encontrado é nos condimentos.

\section{CONCLUSÕES}

As amostras analisadas apresentaram elevado nível de contaminação por coliformes termotolerantes e Staphylococcus coagulase positiva sendo impróprias para consumo humano. A carência de boas práticas na fabricação de produtos frescais, bem como matéria prima de qualidade higiênico sanitária insatisfatória torna-se um risco a saúde do consumidor. Sendo necessário uma fiscalização da fabricação e comercialização destes produtos que devem seguir padrões mais rigorosos.

\section{REFERÊNCIAS BIBLIOGRÁFICAS}

BARBOSA, M. B. C.; THIAGO, M. S.; SANTOS, W. L. M.; MARTINS, N. E. Avaliação da qualidade microbiológica de linguiças frescais de carne suína no município de Sete Lagoas. Revista Higiene Alimentar, São Paulo, v. 17, n. 104/105, p. 20-21, 2003.

BRASIL. Ministério da Saúde. Secretaria de Vigilância Sanitária. Resolução RDC nº 12, de 2 de janeiro de 2001. Regulamento técnico sobre padrões microbiológicos para alimentos. Diário Oficial da República Federativa do Brasil, Brasília, n. 7-E, 10 jan. 2001.

BRASIL. Ministério da Saúde. Política Nacional Alimentação e Nutrição - PNAN. 2000. Disponível em: <htpp://www.saude.gov.brr?. Acesso em: 12 abr. 2005.

BORCH, E.; NESBAKKEN, T.; CHRISTENSEN, H. Hazard identification in swine slaughter with respect to food borne bacteria. International Journal of Food Microbiology, Amsterdam, v. 30, n. 1/2, p. 9-25, 1996.

CHAVES, G. M. C. et al. Avaliação bacteriológica de lingüiça frescal suína comercializada no município do Rio de Janeiro, RJ. Revista Higiene Alimentar, São Paulo, v. 14, n. 13, p. 48-52, jun. 2000.

CHEVALLIER, I.; AMMOR, S.; LAGUET, A.; LABAYLE, S.; CASTANET, V.; DUFOUR, E.; TALON, R. Microbial ecology of a small-scale facility producing traditional dry sausage. Food Control, [S.1.], v. 17, n. 6, p. 446-453, June 2006.

HOFFMANN, F. L.; GARCIA-CRUZ, C. H.; GODOY, J. H. F.; VINTURIM, T. M. Análise microbiológica e sensorial de lingüiça de frango produzida artesanalmente. Boletim do Centro de Pesquisa e Processamento de Alimentos, São Paulo, v. 14, n. 1, p. 40-45, 1996. 
HOLT, J. G. Bergey's manual of systematic bacteriology. 9. ed. Baltimore: Williams \& Wilkins, 1994. 787 p.

INTERNATIONAL COMISSION ON MICROBIOLOGICAL SPECIFICATIONS FOR FOODS. Microrganismos de los alimentos 1: técnicas de análisis microbiológico. 2. ed. Zaragoga: Acribia, 1982. $431 \mathrm{p}$.

MATTICK, K. L.; BAILEY, R. A.; JORGENSEN, F.; HUMPHREY, T. J. The prevalence and number of Salmonella in sausages and their destruction by frying, grilling or barbecuing. Journal of Applied Microbiology, Danvers, v. 93, n. 4, p. 541-547, 2002.

MAURIELLO, G.; CASABURI, A.; BLAIOTTA, G.; VILLANI, $F$. Isolation and technological properties of coagulase negative staphylococci from fermented sausages of Southern Italy. Meat Science, Barking, v. 67, n. 1, p. 149-158, 2004.

MOROT-BIZOT, S. C.; LEROY, S.; TALON, R. Staphylococcal community of a small unit manufacturing traditional dry fermented sausages. International Journal of Food Microbiology, Amsterdan, v. 108, n. 2, p. 210-210, Apr. 2006.
PARDI, M. C. et al. Aspectos higiênicos-sanitários da carne. 2. ed. Goiânia: FG, 1993. 586 p.

TESSSMANN, C.; LIMA, A. S.; DUVAL, E. H.; MACEDO, M. R. P.; SILVA, W. P. Prevalência de Salmonella sp. e Staphylococcus aureus em linguiças do tipo frescal derivadas de carne suína. In: CONGRESSO BRASILEIRO DE MICROBIOLOGIA, 21., 2001. Anais... [S.1.: s.n.], 2001. p. 390.

TUTENEL, A. V.; PIERAD, D.; HOFF, J. V.; CORNELIS, M.; ZUTTER, L. Isolation and molecular characterization of Escherichia coli $\mathrm{O} 157$ isolated from cattle pigs and chickens at slaughter. International Journal of Food Microbiology, Amsterdam, v. 84, n. 1, p. 63-69, 2003.

VIESTEL, M. A. D.; FRANCO, R. M.; CARVALHO, J. C. A. P. Avaliação bacteriológica de lingüiça de frango comercializada no município de Niterói, Estado do Rio de Janeiro, Brasil e a sensibilidade das bactérias frente a antimicrobianos. Revista Brasileira de Ciência Veterinária, Niterói, v. 1, n. 7, p. 9-13, 2000. 